\title{
3 \\ Madonna and piano accordion: Disrupting the order of the world ${ }^{1}$
}

\author{
Elizabeth Burns Coleman
}

In 1997, a poster depicting an icon of the Madonna playing a piano accordion was produced to promote the Adelaide Arts Festival. The Madonna was depicted enthroned against a background that was recognisably of the park that extends from the Adelaide Arts Centre to the Torrens River, with one of the major cathedrals in the background. She was surrounded by outlines of gods from other religions, including Buddha, Ganesh, and an Aboriginal Wandjina. The style of presentation was recognisably Middle Eastern, a point emphasised by the gold mosaic frame, and the 'Greek' lettering of the announcement of the event and its main sponsor, Telstra. It appeared, by all publicity standards, to be a fantastic poster. It was beautiful, and it was rich with connotative association that made it appropriate for the festival. Adelaide is known as 'The city of churches', so the poster was very specifically appropriate to the Adelaide arts festival, as opposed to an arts festival in some other place. A third feature of the poster that made it so good was that the image of the Madonna with an accordion is inclusive of what may be considered a form of high art as well as popular culture. Moreover, the image was inclusive of different religious and community groups and the art of different cultures and, as such, reflected and celebrated a multicultural recognition of the value of the arts across different cultures. However, within weeks, the poster was withdrawn from circulation by the Festival organisation because the Greek Orthodox Church had complained it was an inappropriate and offensive use of one of their icons.

Since 1978, the Zuni people of Mexico have been demanding the repatriation of their war gods, or Ahauutas, from museums around the world, including the Smithsonian. Their case involves two issues: first, in Zuni eyes the Ahauutas are communal property and by definition, it is claimed, consider their ownership by museums not ownership but theft. The second issue is one that concerns us here. According to James Clifford, 'Zuni vehemently object to the display of these figures (terrifying and of great sacred force) as "art". They are the only traditional objects singled out for this objection' ${ }^{2}$ This same kind of issue may arise in relation to the display of replicas of sacred objects. In 1975, an ethnologist at the National Museum of Canada wrote to the director suggesting the removal 
of Iroquoian false face masks on the basis that "The Iroquois consider the masks highly sacred and even "dangerous" objects that should be viewed only at the time of curing rituals'. ${ }^{3}$ The masks were removed five years later, but a proposal to replace them with fibreglass casts of the original was objected to by the Grand Council of Hodenosaunee (or Iroquois Confederacy). The Council denied the existence of a distinction between ritually and commercially carved masks and forbade the exhibition of any masks. It also forbade all forms of reproduction, and the distribution of any information about them. ${ }^{4}$

Both the poster and the display of indigenous artefacts appear to be completely innocuous. The poster did not defile, ridicule or attack Mary or the Church, and the display of the Zuni war god, and the Iroquois false face masks, was simply that - their display. So the objections expressed by the Orthodox Church and the Zuni are mysterious. It is hard to understand why they are objecting, let alone why we might care about their objections. Both cases challenge important values we hold. One case confronts the value of freedom of expression. The second confronts the value of knowledge and the practice of collection for the purposes of study, public education and aesthetic appreciation.

I will argue these two cases are similar, and that this similarity shares features in common with blasphemy, despite the fact that it is not obvious that either of these cases are instances of blasphemy. The attempt to understand what is 'wrong', that is, to grasp what appears to be mysterious in both these cases, will provide us with a better understanding of blasphemy. The structure of this chapter will be as follows. In the first part, I address the idea that these cases are dissimilar, because they involve a symbol on the one hand, and an object on the other. I argue that there is no clear distinction between an object and a symbol. I will also address the concern that the intention to blaspheme, or to offend, is a necessary element of blasphemy. In the third part of the chapter I will draw out some of the important features of these icons and beliefs about their connection to the order of the universe in order to show how we might understand these cases to be connected to each other, and to blasphemy.

\section{Definitions of blasphemy}

In contrast to the delicacy with which the Adelaide Arts Festival treated Orthodox sensibilities in relation to the poster including an image of the Virgin Mary, the National Gallery of Victoria displayed no such misgivings about the display of Andres Serrano's controversial photograph, Piss Christ, which showed an image of a crucifix immersed in the artist's urine, as part of the Melbourne City Festival in 1998. This image might be considered paradigmatic as a case of blasphemy. Various Christian churches sought the removal of the image from public display, and after the negotiations with the gallery and government proved fruitless, the Catholic Archbishop sought a legal injunction against the gallery displaying the image, on the grounds that it was blasphemous, indecent and obscene at law. 
According to Anthony Fisher and Hayden Ramsey, the Archbishop's action was supported by the leaders of other Christian churches, as well as the Jewish and Muslim communities. ${ }^{5}$

Justice Harper of the Supreme Court of Victoria commented in his refusal of the application for the injunction that the photograph 'of itself' might be seen as 'inoffensive', 6 on the grounds that it was beautiful, and showed the crucified Christ in a golden light; the knowledge that the image was created by immersing a crucifix in urine is clearly connected to sacrilege. Sacrilege is the violation of sacred things, and blasphemy, according to Fisher and Ramsey, may be defined as speaking against God or the sacred or ridiculing things consecrated to God or held sacred. ${ }^{7}$ However, as Fisher and Ramsey point out: 'most sacrileges do imply blasphemy in the narrower sense of ridiculing the sacred' ${ }^{8}$ Yet, it might be argued, a plastic crucifix is not a sacred object, at least in any legalist theological sense. A plastic crucifix has not been dedicated or consecrated, or, as is done with church bells, baptised. But a plastic crucifix is a symbol; it represents the sacred. Hence, we should not think that there is a clear distinction between the use of an object, and the use of a symbol.

However, these 'innocuous' cases do not appear to be cases of blasphemy, because there does not seem to be any involvement of a deliberate offence. Deliberate offence, that is, intentional offence, is intrinsic to some definitions of blasphemy. For instance, Roy Perret defines blasphemy as 'an illocutionary act which is a function of the agent's complex intention. In the case of a blasphemous speech act, the speaker intends that the hearer should come to believe something through the recognition of the speaker's intention that the hearer do this'. ${ }^{9}$ Perret supports this intentional interpretation of blasphemy as theologically correct with a quotation from Thomas Aquinas' Summa Theologica:

...a man failing to advert to the blasphemous nature of his words, and this may happen through his being moved suddenly by his passion so as to break out into words suggested by his imagination, without heeding to the meaning of the words: this is a venial sin, and is not blasphemy so called. (Summa Theologica II,ii,13)

This definition suggests that neither kind of case I mentioned, of the display of the Zuni war gods or of the use of the icon, could be considered cases of blasphemy. Neither obviously involves the intention to offend, or a propositional content that the speaker intended the hearer to come to believe.

The Piss Christ example is much more clearly a case of blasphemy than the cases I described in the introduction to my chapter because it appears to involve intention. It is also interesting that apologists for Serrano, and Serrano himself, appealed to the artist's intention in order to argue that it was not blasphemous. Fisher and Ramsay reported that, as the scandal progressed, the artist repudiated 
his earlier claim that his art is simply colourful and deliberately shocking, and asserted that, instead of intending to scandalise, 'his goal all along had been to increase the devotion of his fellow Christians by helping them identify better with Christ in his pain, suffering an humiliation'. 10

In contrast to the definition of blasphemy in terms of intentional offence, Frank J. Hoffman understands blasphemy to be a family of concepts that may be explicated by determining what the religious points are in each case, and determining what social practices exist for homage and desecration in each case. ${ }^{11}$ Hoffman's culturally relative account is consistent with Fisher and Ramsay's position that objects symbolising mysteries 'can only be understood in the context of the religious culture and history of practice from which they emerge'. ${ }^{12}$ Hoffman argues, against Perret, that there is no single perspective from which to define blasphemy. He points out that blasphemy, like obscenity, is often dependent partly on the attitude of the hearer or recipient. He illustrates this point with an 'amusing' story:

Suppose, for example, that there is a pet parrot who is capable of uttering a perverse litany impugning the religious focal points of the 'great religions' of the world. Now, just as the parrot has completed impugning the God of Christianity along with the rest, Aunt Millie, being a frightfully devout (and easily scandalised) Christian lady, indignantly rushes in from the kitchen with the carving knife, ready to lop off the poor parrot's head. Feathers fly, and in the wink of an eye, the badly mangled parrot has sung his (black) swan-song. Aunt Millie is unlikely to be repentant at the thought that the parrot did not intend to blaspheme. $^{13}$

Despite this unpleasant picture of the people who make claims that something is blasphemous as the kind of people who would kill parrots, it does seem arbitrary to insist on a strictly intentional definition of blasphemy, supported by an appeal to religious authority. Given that we are dealing with a phenomenon of offence that has broad agreement across different religions, and is of concern in relation to political issues such as how we should relate to other people's religious beliefs in a multicultural society, we require a less culturally specific, and less religiously specific, definition than the intentional account given by Perret.

But even if intention should not appear as part of the definition of blasphemy, Aunt Millie's lack of appreciation of the parrot's lack of intent is also significant. If intention matters, it may not be the case that it defines whether something was blasphemous, but the level of culpability. We might appeal to the doctrine of double effect: it might be thought that the blasphemy might be permissible, or at least more acceptable, if the blasphemy is the 'unintended side effect' of a good intention, such as the liberation of mixed up human beings from the tyranny 
of apostles of purity, or the education of the general population of the suffering of Christ. In suggesting this use of the doctrine of double effect, I suggest that intention may play a different role from that argued by Perret. Rather than a definition of the act, intention may play a role in our understanding of the moral significance of the act. Similarly, while thinking killing someone is wrong prima facie, we distinguish between different acts on the basis of the killer's intention. For instance, we distinguish between calculated murder, crimes of passion, manslaughter, reckless disregard of other people's safety, killing in war, and justifiable self defence. These distinctions rely at least in part on the intentions of the killer. Similarly, in cases of blasphemy, we may refer to cases where we think it justified (such as the exposure of hypocrisy in the Church, or the exploration of sincere, but heretical, belief) and 'gratuitous' acts of offensive behaviour. $^{14}$

Fisher and Ramsay appear to agree with Hoffman that the cultural context within which the objects are created provides conventional and appropriate responses for how artists may depict certain images, and for what may count as blasphemy. Their argument that Serrano's Piss Christ is unacceptable depends on a conventional account of what it means to immerse a crucifix in urine. It 'can only be a profanation according to the standards of the culture and religion of which it is an artefact, and photographing it and displaying such a deed can only be a blasphemy in that culture' ${ }^{1}{ }$

This may be made as a stronger, universal claim about defilement. In her classic text Purity and Danger, Mary Douglas makes some general, and widely accepted as important, observations about the nature of defilement and its relation to the manner in which we comprehend the world, and organise our societies. ${ }^{16}$ However, the attempt to maintain purity and to avoid defilement should not be seen as a desire that is necessarily totalitarian or fundamentalist. It is something that is part of everyday consciousness. Dirt, she claims, is matter out of place. The coffee in my cup is clean, but if I spill it on clothes, I am dirty. According to Douglas, 'dirt is essentially disorder...Eliminating it is not a negative movement, but a positive effort to organise the environment'. ${ }^{17}$ And she claims that this is not only true of Western secular societies:

If this is so with our separating, tidying and purifying, we should interpret primitive purification and prophylaxis in the same light...rituals of purity and impurity create unity in experience. So far from being aberrations from the central project of religion, they are positive contributions to atonement. By their means, symbolic patterns are worked out and publicly displayed. Within these patterns disparate elements are related and disparate experience is given meaning. ${ }^{18}$

According to Douglas, the categorisation of purity and danger is a major structuring organisation of our society - representing social hierarchy, 
differentiating between groups within and between societies and cultures, but also of structuring our relationship with other people in our societies - and extends beyond human life to the order of the cosmos. We fit into a broader pattern of relationships. Keeping the purity rules therefore maintains a pattern or order to the world. If Douglas is correct, the concept of defilement and purity will be central to all societies, as well as all religions.

In summary, it appears that blasphemy is connected to sacrilege, as what we do with objects, and how we represent them may both involve defilement. The idea of defilement is cross-cultural, and not merely associated with fundamentalist or totalitarian religions. Our intentions do not define whether something is blasphemous, as what counts as the defilement of an object or symbol is dependent on socially agreed norms. It is still not clear, however, that the Madonna and piano accordion is an act of defilement, or that the display of a Zuni god is an example of such contempt. This is what makes them such interesting cases. There is nothing clearly offensive about them. In order to explore what is wrong with such acts, or at least what is perceived to be wrong about such acts, I explore the cognitive content involved in recognising certain kinds of symbols.

\section{Rules of depiction and the order of the world}

The connection between how we may represent a symbol, and how we should respond to one, are linked in Christian tradition. To explain this connection, let me first address the depiction of Mary, and how she may be depicted in icons. Then let me turn to how she is used within religious worship.

Mary holds a special place within Greek Orthodox worship. She was Theotokos. The title, Theotokos, does not simply mean 'Mother of God', but more precisely 'the one who gave birth to the One who is God' ${ }^{19}$ According to John of Damascus, 'The name [Theotokos] in truth signifies the one subsistence and the two natures and the modes of generation of our Lord Jesus Christ' ${ }^{20}$ As 'the one who gave birth to the One who is God', she is represented not only as human, but also as divine. ${ }^{21}$ Within the Western Church, Mary was not considered divine, but as being conferred a special grace by God: she was free from original sin. ${ }^{22}$

As Theotokos, Mary, as well as her icon, was the legitimate subject of Orthodox veneration, but under challenge from iconoclasts, the nature of this veneration needed clarification. Because of her status, Mary has a special place in the distinction between the adoration, latreia, which was reserved for God, and reverence, douleia. Thomas Aquinas thought this distinction did not do full justice to the special position of the Theotokos: she was less than God, but more than an ordinary human being and more than any saint; therefore, she was not 
entitled to lateria, but she was entitled to more than dulia. She was entitled to hyerdulia. $^{23}$

While many contemporary artists may consider the signifier as distinct from the signified, that is, the mental concept may be considered distinct from the material aspect in which it is represented, no similar distinction is made in relation to icons in the Orthodox tradition. Within the Orthodox tradition, the arbitrary nature of the relationship between icon as a symbol and what it represents is denied. In the icon, the image and the idea are inseparable. ${ }^{24}$ George Galavaris writes,

Based on Neo-Platonic theories, the icon is thought basically a mystery, a vehicle for divine power and grace, a means of God's knowledge. It is not merely a symbol of the archetype, but the represented becomes present through the icon. The Council of Nicea of 787 declared that at the adoration of the icon of Christ the faithful should say, 'this is Christ the Son of God'...The icon participates in the holiness of the represented. $^{25}$

Accordingly, the honour displayed to the icon is not directed toward the material object, but to what it represents. It seems that by exploring Platonic ideas we might understand one way in which an image may be understood as a means of spiritual knowledge, and how an image may be considered to participate in a supernatural world.

Plato's understanding of art rests on idealistic assumptions that are first outlined by the Pythagoreans. According to Liberato Santoro-Brienza, for the Pythagoreans, art is a 'therapy of the soul and the body, as a path to attunement with the secret harmony of the universe, and as a key to decode the order of reality'. ${ }^{26}$ The Pythagoreans believed that the entire universe is ruled by mathematical laws and the connection between the cosmic order, numerical proportions and musical harmony provided a conception of beauty in terms of order, measure, proportion and harmony. ${ }^{27}$ Similarly, for Plato, the ground of reality is presupposed by any human activity, and guides artistic activity. Empirical reality is a copy of the true reality that is constituted by perfect forms, and the artist imitates empirical reality. ${ }^{28}$ It follows from this that the arts are inevitably deceptive, as they are twice removed from reality, yet the artist may also be elevated, by inspiration, into the realms of divine harmony. ${ }^{29}$

Philosophers of the Middle Ages developed and elaborated on Greek philosophy, but abandoned the Platonic assumption that art is fundamentally mimetic of empirical reality. Plotinus wrote: 'The arts do not simply copy visible objects, but reach out to principles of nature; the arts provide much themselves, for they can add where there is deficiency; they can do so since in themselves they possess beauty'. ${ }^{30}$ Art, on this understanding, is superior to nature. God 
was thought of as the supreme artist: the whole cosmos is a work of art, and the artist was conceived of as a kind of creator, emulating God's activity. The artist's task was to transform matter into form, and nature into spirit: it was the spiritualisation of matter. ${ }^{31}$ The arts, therefore, have a cognitive, rather than expressive, character; they involve the recognition and recreation of divine order, and art works also enable others to understand the world, as artists produce tokens and symbols of divine perfection. ${ }^{32}$

From this discussion of Medieval conceptions of beauty, Santoro-Brienza reconstructs a picture of what is involved in the experience of beautiful things:

In the presence of beauty, our senses perceive sensory properties that stimulate and gratify the sensory functions. Furthermore, in their immediate apprehension of physical properties, the sensory experiences lead to an intellectual insight into the structure, order, and form of the object, so that the intellect is, in turn, stimulated and gratified by an intuitive grasp of the form... In the harmonious correspondence of the object to all our faculties and, in turn, all our faculties to the object, our senses, intellect, our will are satisfied and result in a condition of delight...The aesthetic experience is, in other words, a harmonious and unifying experience of immediate and intuitive fusion in which subject and object cannot be separated and distinguished. That experience is akin to the experience of love, both physical and spiritual, and of deep reflection, prayer, and the anticipated beatific vision. ${ }^{33}$

In the experience of an image, therefore, we may participate in the nature of the universe and experience unity with it.

In Medieval thought, everything participates, in various degrees, with the perfection of being and, because of this, the different entities share a fundamental trait or a kind of unity. Santoro-Brienza states: 'It is in the light of this principle that we fully understand the Medieval preoccupation with symbolism in general and the conviction that everything is linked to everything else... being in general is one, true good. ${ }^{34}$ However, the Platonic idea that the arts could be deceptive, and fail in this task of spiritualising matter, remained important. Augustine argued that works of art must be partially false insofar as they are the result of imaginative fiction. ${ }^{35}$ There is a dual moral aspect to artistic production. Beauty may align the will and the intellect in desire for and recognition of the form, but it may also mislead. Symbols, therefore, must be reproduced correctly, as they have a devotional purpose.

Within the Greek Orthodox tradition, the liturgical arts are one of the ways in which man becomes divine by grace, and the icon is one of these arts. The prototype of the image belongs to the corrupt world, but its transcendental 
quality can be expressed by the fixation of the type from all that is ephemeral. 'This', Galavaris states,

is why icons cannot be painted according to the imagination of the artists or a living model. The relationship between the prototype and the image would have been lost. For this reason the icon-painter uses manuals...which describe the iconographic scenes and colours to be used. But the use of manuals alone does not guarantee the painting of the sacred image. The painter must himself be "illuminated". 36

In the Painter's Manual, Dionysius of Fourna tells his pupils that they must not 'carry out this work haphazardly, but with the fear of God and with the veneration due to a sacred task'. ${ }^{37}$ The technical skill is only part of this task, as the icon painter is engaged in a work that externalises spiritual reality. The true iconographer is engaged in a work of prayer, so that what he creates stems both from holy tradition and the artist's own experience of the work of grace. ${ }^{38}$

The painting of an icon, therefore, may be seen as a form of meditation, and the manifestation of 'the other' that that subject 'participates in', or makes manifest. Its contemplation is a means of revelation, and provides a means for an audience to engage with this other. The icon used for the poster of the Adelaide Arts Festival is obviously of Mary. I believe that one may safely assume that the painter of the Madonna with a piano accordion was not using a manual. Moreover, I assume that the painter of the Madonna with a piano accordion was not illuminated, let alone offering each stroke of the brush in prayer. The Madonna is out of context - the syntax of the painting is wrong. She is generalised, a symbol of a religious art form among other symbols of religious art. She does not require veneration; she is one among many religious figures. Given this context, we may understand why this image may be considered to be connected to blasphemy, as blasphemy is connected to honour due to the divine or sacred, and the poster subverts or misrepresents what the Greek Orthodox Church takes to be the nature of the icon, and of Mary.

But can we, through this discussion, also understand a religious tradition that is alien to us, such as the Zuni reaction to the display of their war god? There are obvious, and serious, difficulties. One is that the entire Platonic tradition of associating beauty and art is dissimilar to many indigenous conceptions of beauty, and the role of beauty in the production of indigenous artefacts. The anthropological evidence from other cultures, and common sense, should stop us from generalising across cultures on the role of aesthetic experience here.

Yet there are some aspects of many indigenous claims and Platonic thought about the metaphysical nature of representations that appear to be similar. One is the association of the object with what it represents in such a way that it makes 
little sense to say that something is 'a representation'. For instance, I have heard it said that when Maori see images of the ancestors, they do not view or respond to the image as a representation, but respond to the image by greeting the ancestors. The idea that the image and what is represented, or the concept and image, cannot be separated appears to be common to many indigenous concepts of religious objects and to Orthodox understandings of icons. I do not mean to imply that Greek Orthodox metaphysics of symbols are the same as indigenous ones (the Eastern metaphysics of icons is not even the same as the metaphysics of the Western Christian church); rather, my point is that the Orthodox and some indigenous metaphysics of symbols may be contrasted to an understanding of a symbol as a 'mere' symbol. Another aspect of this similarity that appears highly significant in the current discussion is the normative aspects of behaviour that follow from the metaphysical aspects of the symbol, as religious traditions involve norms about how an object may be treated, as well as how it may be produced.

There are norms of behaviour for relating to religious objects, and these norms express the relationship we have with them. For instance, the icon does not merely represent Mary; the image and the idea are considered inseparable. Because of this metaphysical relationship, the honour that is due to the icon is hyerdulia. The acknowledgment within a ritual or religious context is physical. A priest may kiss the icon in recognition. People light candles to the Virgin, cross themselves and genuflect. Similarly, there are norms of remorse in response to blasphemy: the tearing and rending of garments. ${ }^{39}$ Again we find there are norms of responses to indigenous religious objects. The Maori may greet certain objects. Other objects, such as the false face masks of the Iroquios, should not be viewed except within certain contexts.

The norms of acknowledgment are not empty gestures, but are elements of cognition and classification. Nelson Goodman calls these gestures labels. He writes: 'Nods of agreement or dissent, salutes, bows, pointings, serve as labels... The same is true of such activities in response to music as foot- and finger-tappings, head-boppings, and various other motions. That these are called forth by the music, while the conductor's gestures call it forth, does not affect their status as labels; for labels may be used to record or to prescribe "strawberry", "raspberry", "lemon", and "lime" may tell us what is in or what to put in the several containers. ${ }^{40}$ The significance of our responses to music, Goodman thinks, is their role in analysing, organising and registering what we hear. $^{41}$

This relationship between action and concept formation is also held by philosophers who are opposed to a rationalistic understanding of language. D. Z. Phillips draws this point out in his discussion of Wittgenstein and religious observance. I will come back to a discussion of religious observance shortly; for 
the present I wish to focus on the connection between action and categorisation. According to Wittgenstein, religion is a language game, and its basis is not in conceptual understanding but in our responses to certain symbols and sensory experiences. For Wittgenstein, 'primitive reactions', that is, our reactions to pain, colours or sounds, are fundamental to language development. The reactions of jumping with fright, calling colours light or dark or sounds loud or soft, crying out in pain or expressing shock at the pain of others are fundamental to the development of concepts. Wittgenstein wrote: 'The origin and the primitive form of the language-game is a reaction; only from this can the more complicated forms grow. Language...is a refinement; "in the beginning was the deed". 42

Douglas's account of dirt avoidance similarly links sensory impression and the recognition of categories that are expressed in labelling gestures, and explains the process by which those categories are developed and are involved in the recognition of value. Douglas states: 'perceiving is not a matter of passively allowing an organ - say of sight or hearing - to receive a ready-made impression from without...As perceivers we select from all the stimuli falling on our senses only those which interest us, and our interests are governed by a pattern-making tendency, sometimes called schema...' 43 These schemas are learned, first as response, and then named. These names act as labels. Douglas writes: 'Their names then affect the way [sensory impressions] are perceived next time: once labelled they are more speedily slotted into pigeon-holes in future. ${ }^{44}$ Dirt provides an example of how these categories are ordered into a normative pattern of schema. Dirt is a residual category, that which is rejected from our pattern or scheme of classifications - it is out of place.

There is a broader generalisation that may be drawn from these observations that actions are cognitive labels. If actions are cognitive labels, then in making certain physical responses to religious images we are classifying or categorising them. But in failing to respond, we may be failing to categorise or to acknowledge the honour that is due to something as well. Let me give you an example of a non-religious, conventional response to emphasise this point about the withholding of a gesture as a display of a lack of respect. After a musical performance, it is conventionally accepted that clapping hands is an appropriate form of acknowledgment of the performers' skill. Withholding this gesture, or clapping weakly, is a way of expressing dislike. For the performer, a lack of applause must be devastating.

The difference between this kind of labelling of music and the conventional ways in which we pay respect to something and the form of ritualistic response that can be seen in acts of devotion, is that in acts of devotion we also recognise a hierarchy of value and the relationship between the object and observer. Ritualistic or normative responses are not merely the recognition and classification of icons and other religious subjects; they acknowledge a relationship between 
ourselves and what we have classified or recognised through the gesture, and to withhold the gesture may be considered a form of disrespect, or a failure to apprehend its meaning. The Zuni demand their war gods returned because they should not be looked at. Clifford tells us that they are considered terrifying images of great power; as is appropriate to an image of war. Moreover, we can imagine that the properties used to present these gods exemplify the terror of war. It is not surprising to find people averting their gaze at certain horrors, or thinking it would be inappropriate to look upon certain things, such as the horror of war, with the same disinterested appreciation with which they gaze at art.

Even if gazing upon objects such as sacred masks was 'an appropriate' response, indigenous groups might well resent their display. The Grand Council of Hodenosaunee for instance, has a policy of forbidding the display of medicine masks that makes a connection between respect for the masks, and the well-being of the community. The policy states:

The exhibition of masks by museums does not serve to enlighten the public regarding the culture of Hodenesaunee, as such an exhibition violates the intended purpose of the mask and contributes to the desecration of the sacred image. ${ }^{45}$

A claim about the relationship between the 'order' of communities and the treatment of the objects is made explicit. Ruth Phillips reports: 'The statement requests the return of masks to the 'proper caretakers among the Hodenosaunee' because 'it is only through these actions that the traditional culture will remain strong and peace be restored to our communities' ${ }^{46}$

This involves a further element of these rules about how we represent, and acknowledge images or objects that is important in respect to how we comprehend what might be wrong with the failure to show respect, at least from the believer's perspective. This may concern the role of such acts in upholding or maintaining the order of the universe. Douglas refers to this as a primitive world view, but it might also be thought of in terms of God's providence. This perspective seems alien to contemporary, secular scholars, and is thought to be based on mistaken beliefs about the metaphysical relationship between humans and the world in which they live, and the nature of causation. However, as I will argue in the next section, we need not accept either belief, and yet still behave in certain ways that acknowledge respect for certain kinds of representations.

\section{The order of the universe}

Douglas characterises what she calls 'the primitive world view' as a man-centred universe: 'A primitive world view looks out on a universe which is personal in several different senses. Physical forces are thought of as interwoven with the 
lives of persons. Things are not completely distinguished from persons and persons are not completely distinguished from their physical environment. The universe... discerns the social order and intervenes to uphold it' ${ }^{47}$ This is because the transforming energy of the universe is 'threaded onto the lives of individuals so that nothing happens in the way of storms, sickness, blights or droughts except in virtue of these personal links' ${ }^{48}$ The universe is capable of discerning disorder in social relations and social codes, such as whether partners in sexual relationships are related within prohibited degrees, or whether a person has murdered a fellow tribesman or a stranger, and an individual's hidden emotions. ${ }^{49}$ There is a connection between the individual and the world in terms of an order in the world, but this order needs to be maintained. It requires maintenance through the maintenance of purity rules, but also in terms of the structure of relationships.

Such ideas are also found in the history of Western religious thought. We find a similar pattern of thought expressed in the speech Shakespeare gives Ulysses in Troilus and Cressida. The order of the universe includes the orbits of the planets to the season to the offices and custom of societies. When this becomes unbalanced, and when things are not in their order, chaos and calamity follow. What maintains the cosmic order for the Elizabethan is the recognition of degree or value, and the maintenance of social order. Each person and thing has its place, and its place must be recognised and acknowledged. ${ }^{50}$

It would be tempting for a non-believer to interpret the need to maintain order as simply a false understanding of the nature of the universe and of the causal relations in it. In particular, it might be thought, the causal understanding of the relationship between failing to show respect to a symbol and social or natural calamity is false. But, we need not think that a belief in a simple causal relationship is at work here, and this may be the wrong way to understand the nature of religious beliefs and gestures of acknowledgment.

Phillips thinks that we do not need to believe in the order of reality as a chain of being, or to hold a particular metaphysical idea about pictures, to think we would be concerned about doing certain things to images. He agrees with Searle that one of the most powerful aspect's of Wittgenstein's On Certainty is its attack on the philosophical tradition 'according to which all our meaningful activities must be the product of some inner theory...Wittgenstein points out that for a great deal of our behaviour, we just do it'. ${ }^{51}$ The explanations should be considered not to be theories explicitly held, but as means of explicating what is believed after the act has taken place.

He supports this with an empirical experiment, inspired by the idea of 'acting out' a wish suggested by H. O. Mounce. $^{52}$ Mounce supposed that it would be hard for almost anyone to comply with a request that they stick pins into the eyes of a drawing of their mother; but supposing one did do it, and shortly after 
one's mother developed an affliction in the eye and was in danger of going blind, then it would be difficult to resist the feeling, if only momentarily, that there was some connection between the two events. Phillips tested this by asking a group of 40 students whether they would be prepared to stick pins in the eyes of a drawing of their mother, and whether, if their mother developed an affliction in the eye, they would feel guilt. Fifteen of the students said that they would have no difficulty sticking a pin in the eye of the drawing, and if their mother subsequently became ill, they would not feel guilt. Their explanation was that 'it was only a picture', and that there could be no causal connection between the two events. The remaining students said that they would not stick pins in the picture, but that if they did, they would feel guilt if their mother subsequently developed an affliction of the eye. But, Phillips suggests, the students who said this were not positing a causal connection when they said they would feel there was a connection between the two events: '[What] they meant was something like this: they felt that sticking pins in the picture reduces serious possibilities to a game; it plays around with things. When the affliction occurs, an internal relation between "playing around" and the event makes the guilt understandable. ${ }^{53}$ Phillips concludes from this that it is not the case that the students would refuse to stick pins in a drawing of their mother as a consequence of beliefs about the causal connections between the drawing and the outcome, but that a primitive moral response occurs and that people, if asked to reflect on their response, may reply this way. ${ }^{54}$

There must be some explanation of why most people would not stick pins into an image of their mother. Douglas's explanation of 'the primitive world view' in terms of explicit beliefs about an order of the world that needs to be maintained if chaos and misfortune are to be avoided is one way of understanding this connection. But the explanation does not address why Phillips's students would not stick pins in the eyes of a picture of their mother. Moreover, if Douglas's account of this world view could cover all responses to blasphemy, we would expect the primary response to blasphemy to be fear, rather than offence or distress.

Yet the fact that most people, and it seems even people without religious beliefs, would not stick pins into a drawing of their mother can be accounted for in terms of what people hold dear to them, and the respect in which they hold their mothers. This is consistent with Douglas's broader claim about the association between sensory impressions, schema, and values, and Goodman's general claims about our responses being a part of the process of cognition. In recognising something to be an image of 'our mother', we classify such images under a general concept that determines our relationship to it.

An icon of the Virgin Mary may similarly be treated with respect, simply because she is held dear. Non-religious people should not consider such 
sentiments to be alien to them. When a non-religious person tears up a photograph of a person they once loved, their act is one of anger and disrespect; when they refuse to stick pins in the eyes of an image of their mother, or would feel momentary guilt if something later happened to their mother, they also are refusing to treat images as 'mere pictures'. Similarly, we may turn away from representations of war in horror, even if we know they are fictional. Our responses to the image may be understood as recognition of the meaning or content of the image, its value, and an expression of our relationship with it.

\section{Blasphemy and homage}

My interest in this chapter has been to attempt to gain some kind of insight into what is 'wrong' with the seemingly innocent acts of depicting images without following the rules of their depiction, as in the image of a Madonna with a piano accordion, and of viewing depictions of gods and indigenous sacred objects within a museum context. I have attempted to provide as sympathetic account of these claims and of the religious symbols involved as possible. Because I am an atheist, I have not been concerned with an assessment of the truth or adequacy of these ideas, but with their explication, in an attempt to understand a different perspective. Nor has my objective been to provide a moral argument in support of or against claims that these acts are actually wrong. My objective has been to explore whether there is, as my initial intuition suggested, some similarity between seemingly very different acts, and blasphemy.

My conclusion is that the claims that objects should not be displayed in museums and that certain images are inappropriate are connected through the idea that neither act displays an appropriate act of homage or respect to what is represented by the object or symbol. This feature of homage is also central to the concept of blasphemy, if blasphemy is defined as showing contempt for God and religious matters through one's words, thoughts and actions. There is, of course, a difference between the acts of showing contempt of other people's beliefs or of particular beliefs and values, as may occur in intentional blasphemy, withholding acknowledgment (for example, refusing to applaud a performance), and failing to acknowledge because you do not 'understand' what something is. In this third case, absolutely 'nothing goes on' in our heads when we do not genuflect or acknowledge a religious meaning. There is no cognitive process. Just as a parrot may blaspheme without intent, a person may blaspheme without any recognition of value. Just as there are people who would kill a parrot for blaspheming, there are people who would stick pins into the image of their mother, and who cannot understand the perspective of people who would refuse to do this to an image of their mother. Their mistake is to treat images as 'mere' symbols. 


\section{Endnotes}

1 To Robert and John, with my thanks for their conversation, their warmth, and for sharing their ceremonies with me.

2 James Clifford, 1988, The Predicament of Culture: Twentieth-Century Ethnography, Literature and Art, Cambridge (MA): Harvard University Press, p. 209.

3 Memo from Michael K. Foster to Dr Barrie Reynolds, Chief Ethnologist, Canadian Ethnology Service, 10 March 1975, File E7-6R, Canadian Ethnology Service, Canadian Museum of Ethnography. Cited in Ruth B. Phillips, 2004, 'Disappearing Acts: Exposure, Enclosure, and Iroquois Masks', in M.S. Phillips and G. Schochet (eds.) Questions of Tradition, Toronto: University of Toronto Press, p. 74.

4 Ibid., pp. 74-5.

${ }^{5}$ Anthony Fisher and Hayden Ramsey, 2000, 'Of Art and Blasphemy', Ethical Theory and Moral Practice, vol. 3, pp. 137-167, p. 138.

6 Ibid., p. 155.

7 Ibid., p. 139.

8 Ibid., p. 139, note 3.

9 Roy W. Perret, 1987, 'Blasphemy', Sophia, vol 26, no. 2, pp. 4-14, at p. 5.

10 Fisher and Ramsay, op. cit., p. 156. One might question the veracity of this account of Serrano's on the basis that Fisher and Ramsay are at points quite sardonic about Serrano's artistic intentions.

11 F. Hoffman, 1989, 'More on Blasphemy', Sophia, vol. 28, no. 2, pp. 26-35, at p. 30.

12 Fisher and Ramsay, op. cit., p. 157.

13 Ibid., p. 28.

14 People may accept the doctrine as a factor in determining moral culpability, but, like Fisher and Ramsay, remain dubious of the artist's claims about his or her intention or, like Webster, remain dubious that the artist's intention is relevant to the interpretation of the work.

15 Fisher and Ramsay, ibid., pp. 157-8.

16 Mary Douglas, 1966, Purity and Danger, London: Routledge and Kegan Paul.

17 Ibid., p. 2

18 Ibid., pp. 3-4.

19 Jaroslav Pelikan, 1990, Igmago Dei: The Byzantine Apologia for Icons, The A.W. Mellon Lectures in the Fine Arts, 1987, The National Gallery of Art, Washington, D.C.: Princeton University Press, p. 134.

20 Ibid., p. 135.

21 Ibid., p. 142.

22 Ibid., p. 140.

23 Ibid., p. 139.

24 Ibid., p. 3.

25 George Galavaris, 1981, The Icon in the Life of the Church, Leiden: E. J. Brill, pp. 3-4.

26 Liberato Santoro-Brienza, 2003, 'Art and Beauty in Antiquity and the Middle Ages', in Stephen Davies and Ananta Ch. Sukla (eds.), Art and Essence, Westport, Conneticut: Praeger, p. 56.

27 Ibid., p. 57.

28 Ibid., p. 58.

29 Ibid., pp. 58-9.

30 Plotinus 1966-88, Enneades, v 8, 1, translated by Liberato Santoro-Brienza, ibid., p. 63.

31 Ibid.

32 Aquinas, In De Dev. Nom., IV, lectio 5, translated by Liberato Santoro-Brienza, ibid., p. 70.

33 Ibid., p. 70.

34 Ibid., p. 69.

35 Ibid., p. 63.

36 Galavaris, op. cit., p. 4.

37 Cited in John Baggley, 1987, Doors of Perception: icons and their spiritual significance, London: Mowbray, p. 55.

38 Ibid. 
39 Helen Pringle, 2006, 'Are we capable of offending God? Taking blasphemy seriously', in Elizabeth Burns Coleman and Kevin White (eds.), Negotiating the Sacred: Blasphemy and Sacrilege in a Multicultural Society, Canberra: ANU E Press, pp. 31-43, at p. 32.

40 Nelson Goodman, 1968, Languages of Art, Indianapolis: The Bobbs-Merrill Co. Inc., p. 61.

41 Ibid., p. 62.

42 Ludwig Wittgenstein, Culture and Value, (translated by Peter Winch, 1980, Basil Blackwell, 1980, p. 31) cited in D.Z. Phillips, 1993, "Primitive reactions and the reactions of primitives", in D.Z. Phillips, Wittgenstein and Religion, New York: St Martin's Press, p. 114.

43 Douglas, op. cit., p. 36.

44 Ibid. p. 36.

45 Cited in Ruth Phillips, op. cit., p. 75.

46 Ibid..

47 Douglas, op. cit., p. 88.

48 Ibid., p. 85.

49 Ibid., p. 87.

50 E.M.W. Tillyard, 1974 (1943), The Elizabethan World Picture, Harmondsworth: Penguin, pp. 17-8.

51 John Searle, 1987, 'Wittgenstein: Dialogue with John Searle', (in The Great Philosophers, Bryan

McGee, BBC Books, p. 346,) cited in D.Z. Phillips, 'Searle on Language-Games and Religion', op. cit., p. 28.

52 D. Z. Phillips, 'Primitive reactions and the reactions of primitives' op. cit., p. 115-6.

53 Ibid., p. 116.

54 Ibid. 